\title{
A novel adaptive synchronous rectification system for low output voltage isolated converters
}

\author{
M. Rodríguez, Student Member, IEEE, D. G. Lamar, Member, IEEE, M. Arias, Member, IEEE, \\ R. Prieto, Member, IEEE and J. Sebastián, Member, IEEE
}

\begin{abstract}
The design of efficient, isolated low output voltage converters is a major concern due to their widespread use. One of the preferred methods used to maximize their efficiency is synchronous rectification, i.e. the replacement of the secondary side diodes with MOSFETs to decrease conduction losses. However, depending on the topology being used, synchronous rectification might not provide the required efficiency improvement or even be easily implemented. This paper presents a novel synchronous rectification system that can be applied to converters with symmetrically-driven transformers and to converters from the Flyback family; in both cases, the proposed system adaptively generates a control signal that controls a synchronous rectifier MOSFET placed in paralell with each diode, turning it on during the conduction intervals of the diodes. The proposed system uses only information from the secondary side, thus avoiding breaking the isolation barrier; it can be built using a few low cost analog components, it is reliable and simple, and could be easily implemented in an integrated circuit. Up to a $3 \%$ improvement is demonstrated in a 3.3-5 V, $120 \mathrm{~W}$ Push-Pull converter and up to a $2.5 \%$ improvement is obtained in a $5 \mathrm{~V}, 50 \mathrm{~W}$ Flyback converter, both of them designed for telecom applications.
\end{abstract}

Index Terms-DC-DC power converters, Power conversion, Switching converters

\section{INTRODUCTION}

$\mathbf{L}$ OW output voltage converters are widely used in many applications. The supply of integrated circuits, microprocessors and FPGAs is undoubtely one of the most important; said loads are usually supplied with voltages that can range from $1.2 \mathrm{~V}$ to $5 \mathrm{~V}$, thus demanding high output currents from the converter. To increase the efficiency of these converters, transistors must replace diodes in the rectification stage, in a technique usually called Synchronous Rectification (SR). A detailed comparison between the use of diode rectifiers versus synchronous rectifiers can be found e.g. in [1].

In the majority of low output voltage applications, MOSFET transistors are used as synchronous rectifiers, mainly due to

Manuscript received May 21, 2010. Accepted for publication October 9, 2010.

Copyright (C) 2010 IEEE. Personal use of this material is permitted. However, persmission to use this material for any other purposes must be obtained from the IEEE by sending a request to pubs-permissions@iee.org.

This work was supported by the Spanish Ministry of Science and Innovation under grant AP2006-04777 and under the Consolider Project RUE CSD200900046.

M. Rodríguez, D. G. Lamar, M. Arias and J. Sebastián are with the Electronic Power Supply Systems Group, Universidad de Oviedo. Edificio Departamental 3, Campus de Viesques s/n, 33204 Gijón, Spain (contact email: rodriguezmiguel.uo@uniovi.es).

R. Prieto is with the Centro de Electrónica Industrial, Universidad Politécnica de Madrid, E. T. S. Ingenieros Industriales. C/ José Gutiérrez Abascal, 2. 28006 Madrid.

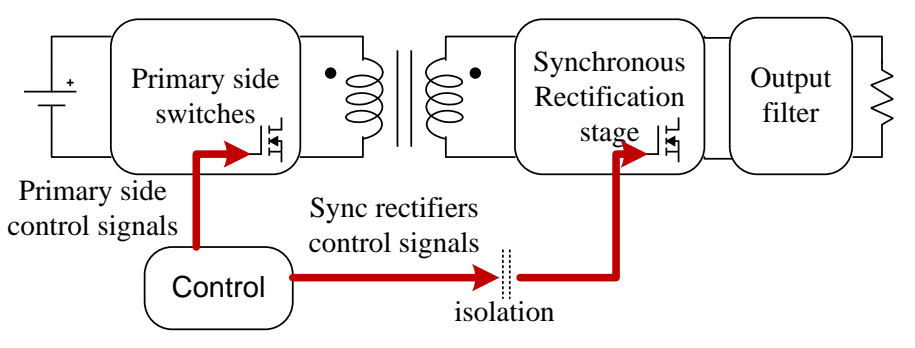

(a)

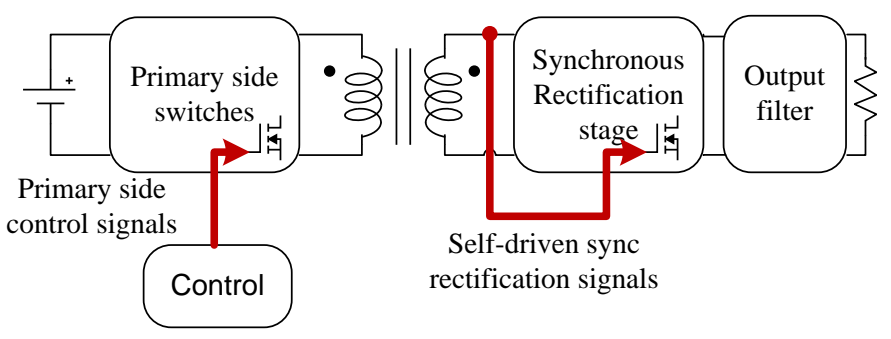

(b)

Figure 1. Isolated converter block diagram: (a) with EDSR; (b) with SDSR.

their low on-resistance that minimizes conduction losses. The major drawback regarding the use of synchronous rectifiers is the need for a control signal that has to turn on the transistor during the intervals when the diodes would be conducting, avoiding short circuits in the secondary side. Traditionally, two different techniques have been used to control the synchronous rectifiers [2]. The first one is called External-driven Synchronous Rectification (EDSR) and it is shown in Fig. 1a. In this technique, the control signals are generated by an auxiliar circuit that guarantees the appropriate timing, and thus the transistors can be activated during the whole rectification period and the efficiency can be maximized [3]. However, in isolated applications, the control signals that are usually generated in the primary side have to be transmitted to the secondary side, thus increasing complexity and cost.

Fig. 1b shows the second technique, called Self-driven Synchronous Rectification (SDSR). In SDSR the control signals are obtained directly from the power stage; therefore, the specific topology being used determines the conduction intervals of the rectifiers. SDSR is preferred in isolated applications because the control signals are usually obtained directly from the power transformer, thus yielding a very simple, efficient and reliable rectification stage [4]-[6]. Several modifications to the SDSR method have been proposed to improve its performance in certain applications [7]-[13], although the 
complexity of some of the solutions finally led to a hybrid scheme, as in [11], [12]. However, in many topologies the driving signals cause the synchronous rectifiers to be off during a certain part of the switching cycle, thus causing conduction of the parasitic diodes and decreasing efficiency. For instance, in topologies with symmetrically-driven transformers, as Halfbridge, Full-bridge and Push-Pull topologies, the synchronous rectifiers are not activated during the dead times of the transformer. This fact causes a noticeable decrease in the efficiency for high input voltages (i.e. low duty cycles). In telecom applications in which a wide input voltage range is common $(18-36 \mathrm{~V}$ in rated $24 \mathrm{~V}$ converters and $36-72 \mathrm{~V}$ in rated $48 \mathrm{~V}$ converters), commercial products might suffer an efficiency drop as high as $4 \%$ (see for instance the ASQ24 family [14]). Several solutions have already been proposed to solve this problem [15]-[17]. Reference [15] proposes a system based on additional windings to drive the synchronous rectifiers. It provides a very good performance but requires a very careful magnetic design, which can compromise the behavior of the system and increase the cost of the converter. References [16], [17] use an additional controlled voltage source to force the synchronous rectifiers to be on during the dead times. This system also performs well, but again requires a careful design of the voltage source, which in turn has to be regulated using extra circuitry that complicates the system.

This paper proposes a novel synchronous rectification scheme to be used in isolated converters that has been called Adaptive Off-Time Synchronous Rectification (AOTSR). The proposed system extends the time interval when the synchronous rectifiers are activated in topologies with symmetrically-driven transformers (Half and Full-bridges and Push-Pull) that implement SDSR. The system can also be used as a complete synchronous rectification system in converters from the Flyback family (Flyback, isolated SEPIC, Ćuk and Zeta). In this kind of applications the use of synchronous rectification has also been explored throughout custom circuitry: [18] uses very simple analog circuitry to control a synchronous rectifier in a low cost Flyback converter, but only when it operates in Discontinuous Conduction Mode (DCM). Several commercial ICs, as the IR11672 or the NCP4302, allow to control synchronous rectifiers using only information from the secondary side in Flyback and HalfBridge converters, but the use of these ICs is currently not very widespread. Furthermore, those ICs turn on or off the rectifiers by measuring the instantaneous voltage across it, thus having relatively high noise-sensitivity. With the use of additional switches in converters with symmetrically-driven transformers with SDSR, and with a single switch in parallel with the diode in converters from the Flyback family, the AOTSR system provides a noticeable increase in the efficiency; it can be used with standard, primary-side control ICs, it can be implemented using very simple, low cost analog circuitry and it is suitable to be easily integrated. The proposed system is intended to work with fixed frequency converters that operate in Continous Conduction Mode (CCM). CCM operation is the usual design case for the target converters at full load, which is when synchronous rectification provides better results with respect to the use of diodes.
This paper is organized as follows: section II presents the AOTSR concept and its theoretical basics. Section III proposes a simple analog implementation of the AOTSR which can be used for both types of converters, while section IV presents several experimental results that show the efficiency improvement that can be achieved. Finally, section V states the conclusions.

\section{The Adaptive OfF-Time Synchronous RECTIFICATION CONCEPT}

For the sake of clarity, this section is divided in two parts: subsection II-A presents the AOTSR concept for converters with symmetrically-driven transformers, whereas subsection deals with converters from the Flyback family. Although the AOTSR concept is very similar in both cases, conceptually speaking the derivations of the main equations and the desired waveforms are slightly different, and therefore they are explained separately.

\section{A. Converters with symmetrically-driven transformers}

Fig. 2a shows a center-tapped SR stage typical of converters with symmetrically-driven transformers; only the output inductance of the filter stage is shown for simplicity. In the first half of the switching cycle, $T_{s w}, S R 1$ is activated during the interval $\left[0, d T_{s w}\right]$, while during $t_{d e a d, 1}$ its gate voltage falls to zero and the parasitic diodes carry the inductance current. During the second half of the switching cycle the same happens with $S R 2$. The conversion ratio in this symmetricallydriven converters can be expressed as:

$$
\frac{V_{\text {out }}}{V_{\text {ct,peak }}}=2 d, 0.5 \geq d \geq 0,
$$

$V_{c t, p e a k}$ depending on the topology; for instance, assuming a transformer turns ratio of $n: 1: 1$, in a Half-bridge converter $V_{c t, \text { peak }}=\frac{V_{i n}}{2 n}$, whereas in a Full-bridge and in a Push-Pull converter $V_{c t, \text { peak }}=\frac{V_{i n}}{n}$.

Figure $2 \mathrm{~b}$ shows a general block diagram of the proposed AOTSR and its corresponding operating waveforms. The idea is to connect an additional MOSFET in paralell with each main synchronous rectifier. These main synchronous rectifiers are still self-driven, as in a conventional SDSR design, thus having the advantages previously stated in Section I. The additional transistors, $A R 1$ and $A R 2$, which are placed in parallel with the main rectifiers $S R 1$ and $S R 2$, are controlled by the same signal, $v_{A R}(t) . A R 1$ and $A R 2$ are in charge of carrying the output current only during the main synchronous rectifiers offtime intervals, $t_{\text {dead,1 }}$ and $t_{\text {dead,2 }}$. Such arrangement, although requires additional transistors, keeps the advantages of SDSR and also eases thermal management. $t_{\text {dead,1 }}$ and $t_{\text {dead,2 }}$ can be easily found from Fig. 2:

$$
\begin{aligned}
& t_{d e a d, 1}=t_{d e a d, 2}= \\
& =\frac{T_{s w}}{2}-d T_{s w}=\frac{T_{s w}}{2}(1-2 d), 0<D<0.5 .
\end{aligned}
$$

As (2) shows, the dead times change with the duty cycle; therefore, the system has to adaptively change $v_{A R}(t)$ for 


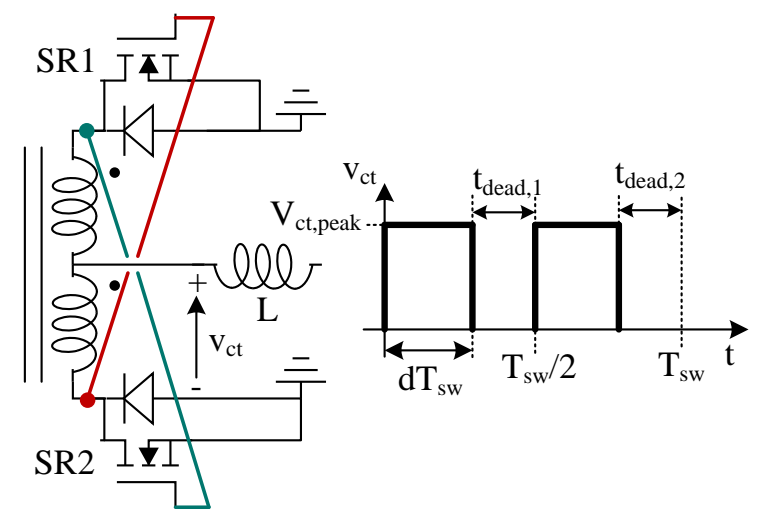

(a)

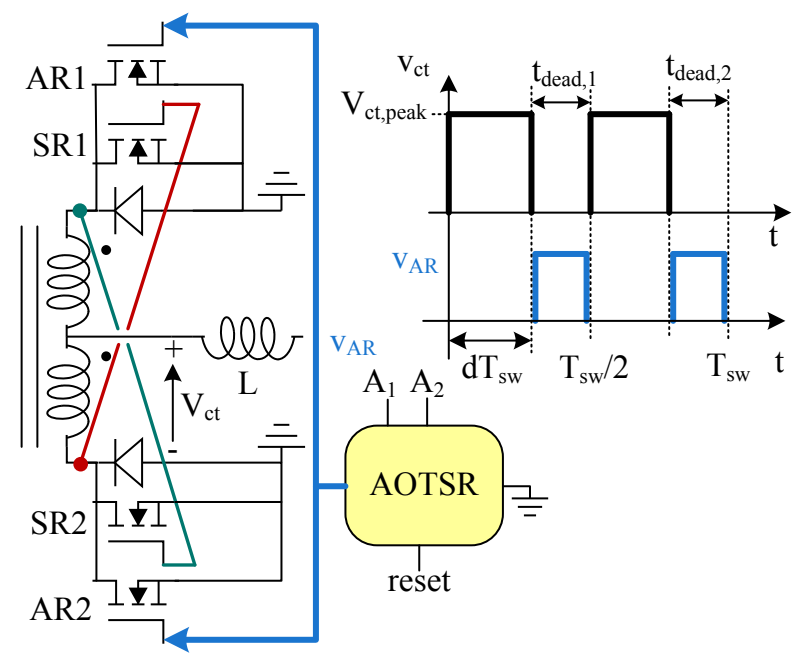

(b)

Figure 2. (a) Center-tapped rectifier with SDSR and corresponding waveforms in a converter with a symmetrically-driven transformer; (b) proposed AOTSR and desired control waveforms for the additional rectifiers AR1 and AR2.

different operating conditions, avoiding an overlap with the control signals of the primary switches, situation that would cause a short-circuit in the secondary side. Furthermore, it has to generate $v_{A R}(t)$ using only information from the secondary side of the transformer to avoid breaking the isolation barrier; said information has been represented arbitrary in Fig. 2b by the input terminals $A_{1}, A_{2}$ and reset, that have to be connected to appropriate points of the secondary circuit to achieve the desired adaptive behavior.

\section{B. Converters from the Flyback family}

Figures 3 and 4 show the four isolated converters that arise from the buck-boost converter, i.e. the Flyback family of converters. Figs. 3a and 3b show a Flyback and an isolated SEPIC converter, respectively, while Fig. 3c shows their corresponding operating waveforms. Figs. $4 \mathrm{a}$ and $4 \mathrm{~b}$ show the Zeta converter (inverse SEPIC converter) and the isolated Ćuk converter, respectively. Fig. $4 \mathrm{c}$ shows the corresponding waveforms. Note that in each group of figures a voltage that fulfills the volts-second balance is highlighted ( $V_{\text {sec }}$ in Fig. 3 and $V_{L}$ in Fig. 4). The conversion ratio in these four isolated,

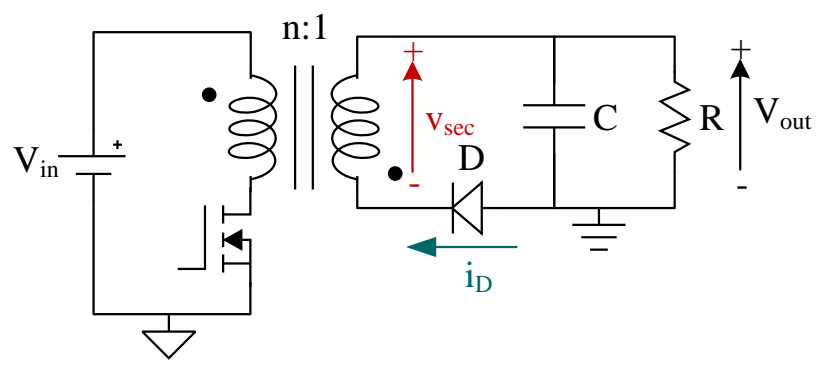

(a)

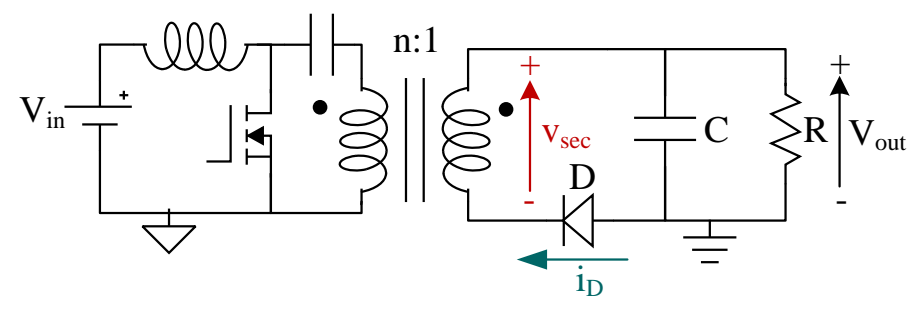

(b)

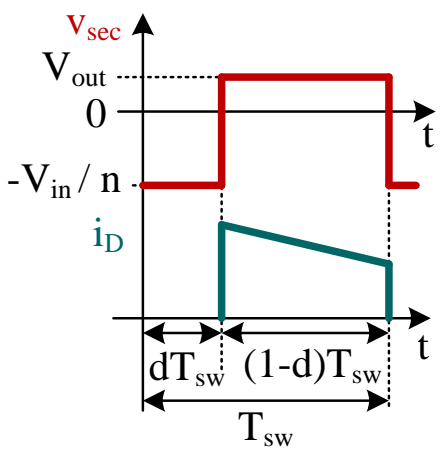

(c)

Figure 3. (a) Flyback converter; (b) isolated SEPIC converter; (c) ideal operating waveforms.

buck-boost derived converters is:

$$
\frac{V_{\text {out }}}{V_{\text {in }}}=\frac{1}{n} \frac{d}{1-d} .
$$

In these four converters the output diode $D$ carries the output current during $(1-d) T_{s w}$.

Figure 5 shows the proposed synchronous rectification scheme and its corresponding waveforms in the case of the Flyback converter. A MOSFET that acts as the synchronous rectifier, $A R$, must be added in paralell with $D$. The AOTSR system generates a control pulse, $v_{A R}(t)$, that turns $A R$ on during $(1-d) T_{s w}$, avoiding an overlap with the control signal of the primary switch. Once again the system has to adaptively generate $v_{A R}(t)$ disregarding of the value of the duty cycle and using only information from the secondary side. The AOTSR block represented in Fig. 5 is the same as the one depicted in Fig. 2b; it is shown in the following section that the same implementation can be used for both cases, just connecting the corresponding terminals $A_{1}, A_{2}$ and reset to appropriate points of the secondary side. Furthermore, the same implementation can also be directly applied to the isolated SEPIC, Ćuk and Zeta converters: a MOSFET must 


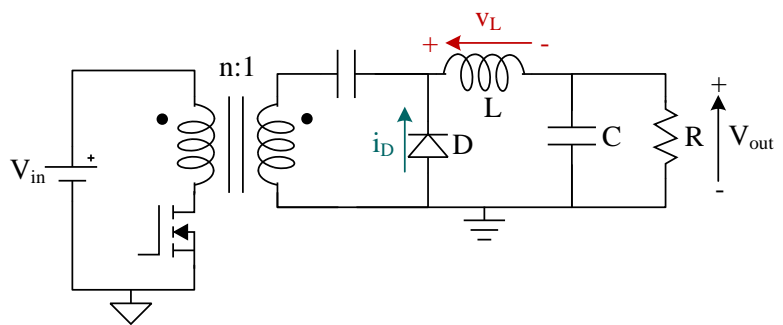

(a)

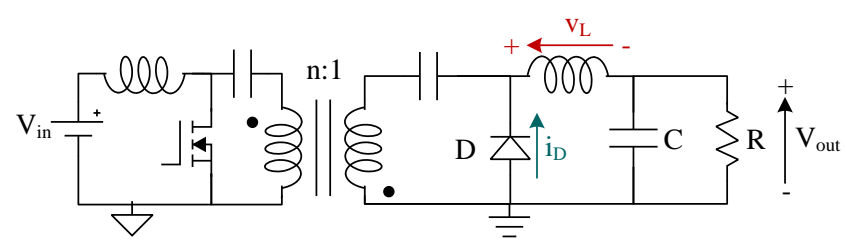

(b)

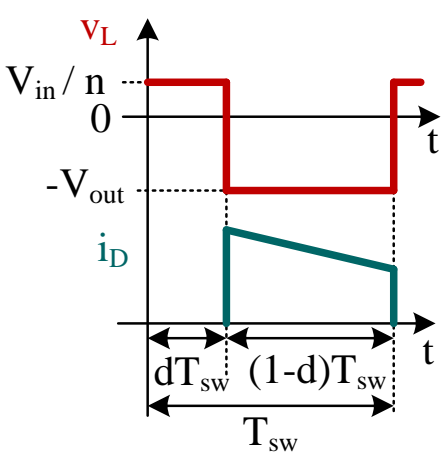

(c)

Figure 4. (a) Isolated Zeta converter (inverse SEPIC); (b) isolated Cuk converter; (c) ideal operating waveforms.

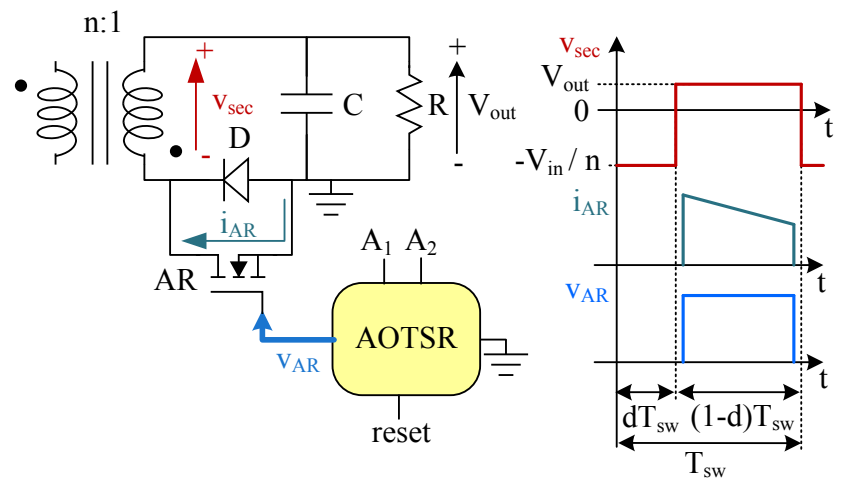

Figure 5. Proposed AOTSR system and corresponding waveforms in a Flyback converter.

be placed in paralell with $D$ and activated during $(1-d) T_{s w}$. Note that in these four converters the auxiliary synchronous rectifier is ground-referenced.

\section{IMPLEMENTATION OF THE ADAPTIVE OFF-TIME SYNCHRONOUS RECTIFICATION}

Fig. 6 shows the proposed implementation of the AOTSR system. It is comprised of a peak detector $\left(D_{p d}\right.$ and $\left.C_{p d}\right)$, two current mirrors (one made up of $T_{1}$ and $T_{2}$, and the second made up of $T_{3}$ and $T_{4}$ ) and a comparator. The key idea of the circuit is to charge $C_{p d}$ to the peak voltage between $A_{1}$ and $A_{2}$ in each switching cycle:

$$
V_{C p d}=\max \left\{V_{A 1}(t)-V_{A 2}(t)\right\}_{T_{s w} \geq t \geq 0} .
$$

Within a switching cycle, $V_{C p d}$ is assummed to remain constant. $C_{p d}$ must be selected small enough to avoid any change in the operation of the converter, and at the same time it should be able to maintain its voltage approximately constant during a switching cycle, taking into account the current demand of the AOTSR circuitry. A capacitance in the range of a few hundreds of nanofarads is suitable for this application. Neglecting voltage drops in the transistor junctions, the current generated by the first current mirror, $T_{1}$ and $T_{2}$, is:

$$
I_{T_{1}}=I_{T_{2}}=\frac{V_{C p d}}{R_{1}} .
$$

$I_{T_{1}}$ generates a voltage at the positive input of the comparator equal to:

$$
V_{+}=R_{2} \cdot \frac{V_{C p d}}{R_{1}}=\frac{R_{2}}{R_{1}} V_{C p d} .
$$

Neglecting the voltage drop across $D_{p d}$, the current generated by the second current mirror $\left(T_{3}\right.$ and $\left.T_{4}\right)$ is:

$$
I_{T_{3}}=I_{T_{4}}=\frac{V_{A 1}}{R_{\text {ramp }}},
$$

$V_{A 1}$ being the voltage at $A 1$. Following Fig. $6, I_{T_{4}}$ charges $C_{r a m p}$ generating the following voltage waveform at the negative input of the comparator:

$$
V_{-}(t)=\frac{V_{A 1}}{R_{\text {ramp }} C_{\text {ramp }}} t .
$$

The time when the voltage ramp $V_{-}$equals $V_{+}$determines the lenght of the control pulse, $t_{\mathrm{VAR}}$. Using (6) and (8):

$$
\begin{aligned}
& \frac{V_{A 1}}{R_{\text {ramp }} C_{\text {ramp }}} t_{\mathrm{VAR}}=\frac{R_{2}}{R_{1}} V_{C p d} \Rightarrow \\
& \Rightarrow t_{\mathrm{VAR}}=R_{\text {ramp }} C_{\text {ramp } p} \frac{R_{2}}{R_{1}} \frac{V_{C p d}}{V_{A 1}} .
\end{aligned}
$$

Therefore, $t_{\mathrm{VAR}}$ depends on the values of $R_{1}, R_{2}, C_{\text {ramp }}$ and $R_{\text {ramp }}$, as long as on the voltage at $A 1$ and on the peak voltage between $A 1$ and $A 2$, i.e. the voltage $V_{C p d}$.

From Figs. $2 \mathrm{~b}$ and 5, it is apparent that the AOTSR must ensure that $v_{A R}(t)$ goes to zero during the conduction intervals of the primary side transistors (during $\left[0, d T_{s w}\right]$ and $\left[T_{s w} / 2, T_{s w} / 2+d T_{s w}\right]$ in converters with symmetricallydriven transformers and during $\left[0, d T_{s w}\right]$ in converters from the Flyback family), to avoid overlapping. This is achieved through the reset transistor $M_{\text {reset }}$ : assumming that the reset terminal is connected to a voltage that goes high during the conduction intervals of the main transistors, both inputs of the comparator will be pulled low during such intervals. Note from Fig. 6 that the voltage at the negative input is slightly higher than the voltage at the positive input, due to the different forward voltage drop of each diode: $V_{-}$is pulled down to the forward voltage drop of the PN diode $D_{\text {reset- }}$, which is slightly higher than the forward voltage drop of the Schottky diode $D_{\text {reset+ }}$, ensuring that $v_{A R}(t)$ is 0 whenever $M_{\text {reset }}$ is 


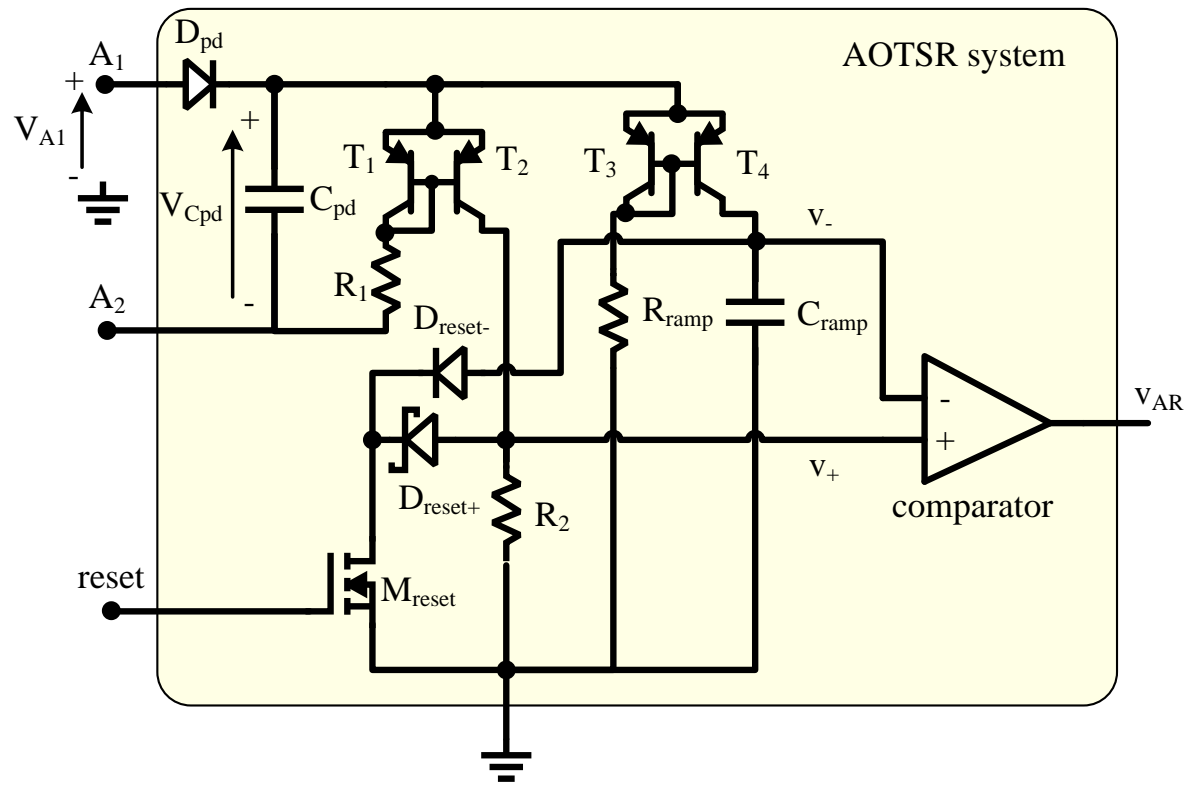

Figure 6. Circuit implementation of the AOTSR system.

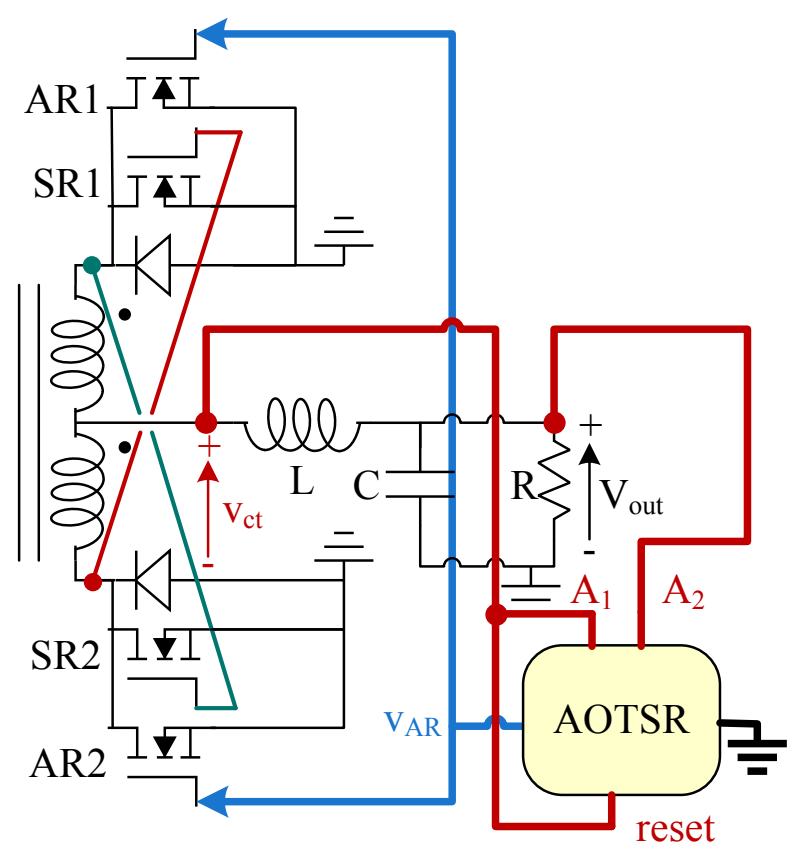

Figure 7. Connection of the proposed AOTSR system in a converter with a symmetrically-driven transformer.

activated. This reset mechanism guarantees that the proposed system causes no overlap, even in the presence of sudden changes of the duty cycle. Several alternatives are possible to avoid DCM operation of the proposed AOTSR; for instance, if the current through the rectifier becomes negative and at the same time $V_{A R}$ is high, then $V_{A R}$ can be immediately pulled low. This can be done using very few additional components.

\section{A. Converters with symmetrically-driven transformers}

Fig. 7 shows the proposed system in the case of converters with symmetrically driven transformers. $A_{1}$ and $A_{2}$ must be connected to the center tap of the transformer and to the output terminal, respectively. The reset terminal is also connected to the center tap, thus reseting the AOTSR during the desired intervals. With the aforementioned connections, $V_{C p d}$ and $V_{A 1}$ are:

$$
\begin{aligned}
& V_{C p d}=V_{c t, p e a k}-V_{o u t} \\
& V_{A 1}=V_{c t, p e a k} .
\end{aligned}
$$

Using (10), (11) and (1), (9) can be written as:

$$
t_{\mathrm{VAR}}=\frac{R_{2}}{R_{1}} R_{\text {ramp }} C_{\text {ramp }}(1-2 d) .
$$

Now choosing $R_{1}, R_{2}, R_{\text {ramp }}$ and $C_{\text {ramp }}$ as:

$$
R_{\text {ramp }} C_{\text {ramp }} \frac{R_{2}}{R_{1}}=k \frac{T_{s w}}{2},
$$

$k$ being a safety factor to ensure that no short circuits take place, (9) can be written as:

$$
t_{\mathrm{VAR}}=k \frac{T_{s w}}{2}(1-2 d) .
$$

Comparing (14) with (2), it is apparent that, with the aforementioned selection of the component values described by (13), the duration of the pulse can be made as close to the duration of the dead times as desired; in practice $k$ will be chosen to be around 0.9 to avoid overlapping and at the same time maximize $t_{\mathrm{VAR}}$. Furthermore, (14) yields the desired adaptive behavior: the higher the duty cycle, the shorter $t_{\mathrm{VAR}}$. Fig. 8 shows the operating waveforms of the AOTSR for two different values of the duty cycle.

\section{B. Converters from the Flyback family}

Fig. 9 shows the proposed system in the case of a Flyback converter. In this case, $A_{1}$ and $A_{2}$ must be connected to the cathode of $D$ and to the output, respectively. The reset terminal is also connected to the cathode of $D$, again pulling 


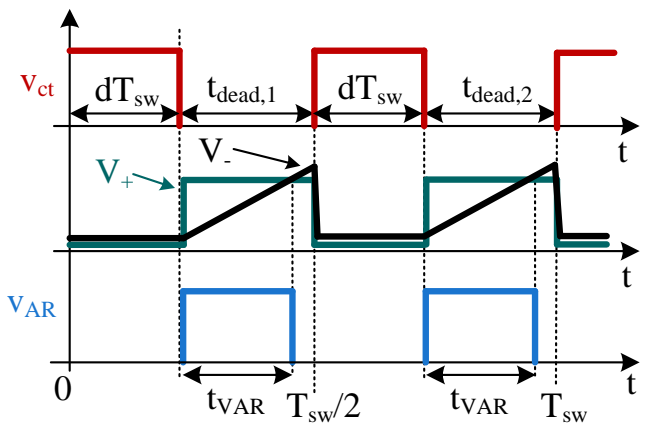

(a)

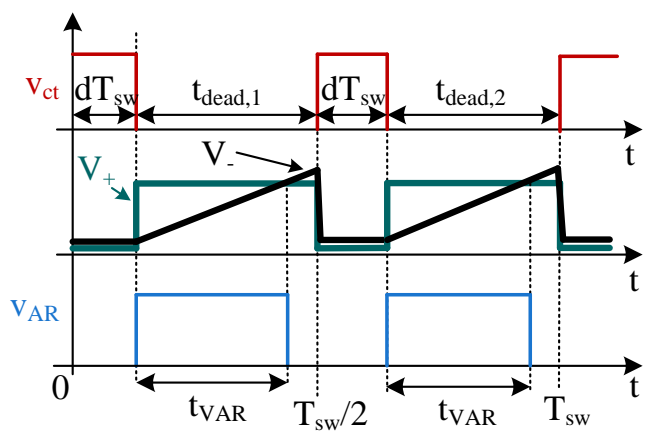

(b)

Figure 8. Operating waveforms of the AOTSR in a converter with a symmetrically driven transformer: (a) $\mathrm{d} \approx 0.25$; (b) $\mathrm{d} \approx 0.15$.

$v_{A R}(t)$ low during the desired intervals. With the aforementioned connections, $V_{C p d}$ and $V_{A 1}$ are:

$$
\begin{aligned}
& V_{C p d}=\frac{V_{\text {in }}}{n} \\
& V_{A 1}=\frac{V_{\text {in }}}{n}+V_{\text {out }} .
\end{aligned}
$$

Using (15), (16) and (3), (9) can now be written as:

$$
t_{\mathrm{VAR}}=\frac{R_{2}}{R_{1}} R_{\text {ramp }} C_{\text {ramp }}(1-d) .
$$

Now choosing $R_{1}, R_{2}, R_{\text {ramp }}$ and $C_{\text {ramp }}$ fulfilling:

$$
\frac{R_{2}}{R_{1}} R_{\text {ramp }} C_{\text {ramp }}=k T_{s w},
$$

$k$ being a safety factor to ensure that no short circuits take place, (9) can be written as:

$$
t_{\mathrm{VAR}}=k T_{s w}(1-d) .
$$

Once again, it is apparent that, with the aforementioned selection of the component values, the duration of the pulse can be made as close to the duration of the diode conduction time as desired; in practice $k$ will be chosen to be around 0.9 to avoid possible short circuits and at the same time maximize $t_{\mathrm{VAR}}$. Equation (19) again yields the desired adaptive behavior: the higher the duty cycle, the shorter $t_{\mathrm{VAR}}$. Fig. 10 shows the operating waveforms of the AOTSR for two different values of the duty cycle.

Figure 9 is also applicable to the isolated SEPIC converter, whereas the appropriate connections in the case of the isolated Zeta and Ćuk converters are shown in Fig. 11

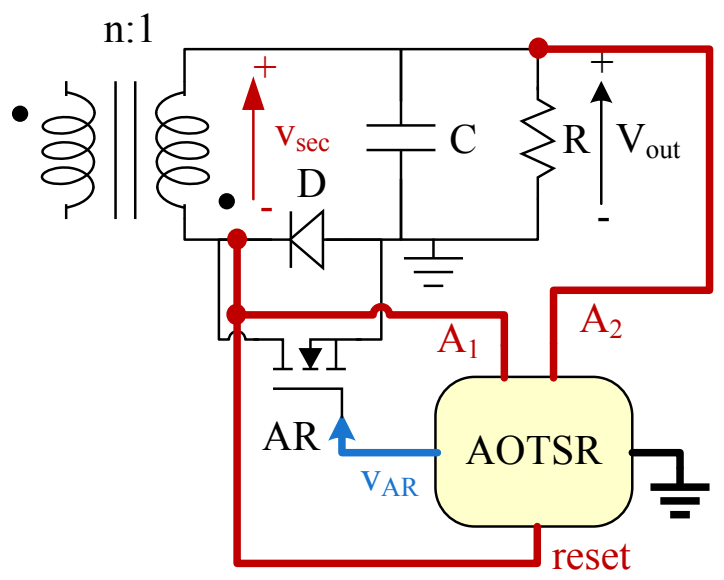

Figure 9. Connection of the proposed AOTSR system to a Flyback converter.

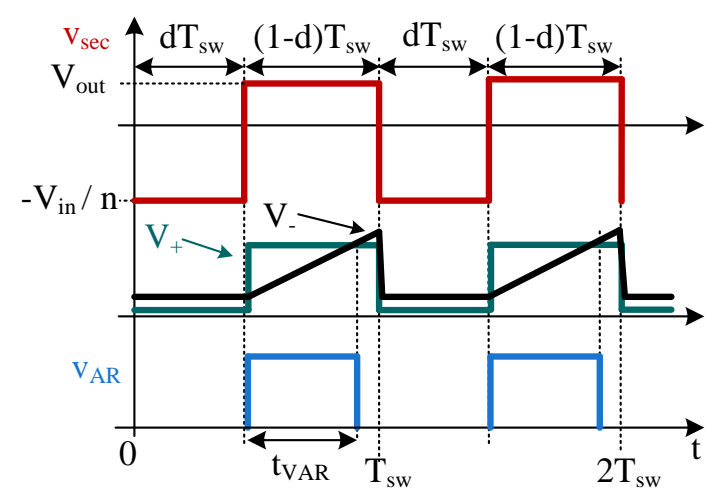

(a)

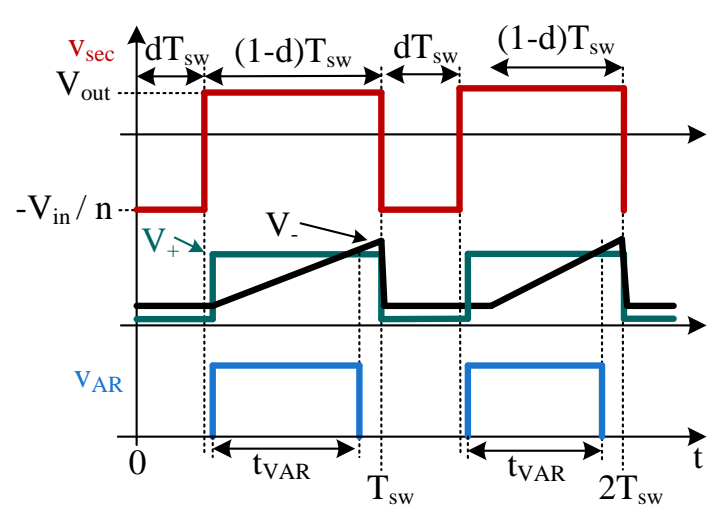

(b)

Figure 10. Operating waveforms of the AOTSR in the Flyback converter: (a) $\mathrm{D} \approx 0.5$; (b) $\mathrm{D} \approx 0.3$.

\section{EXPERIMENTAL RESULTS}

Two converters were used to test the proposed system. A $100 \mathrm{~W}$ Push-Pull converter was used to implement the AOTSR system in a converter with a symmetrically-driven transformer; a $50 \mathrm{~W}$ Flyback converter was selected to test the system in an isolated buck-boost derived topology. The results obtained are shown in the following sections. 


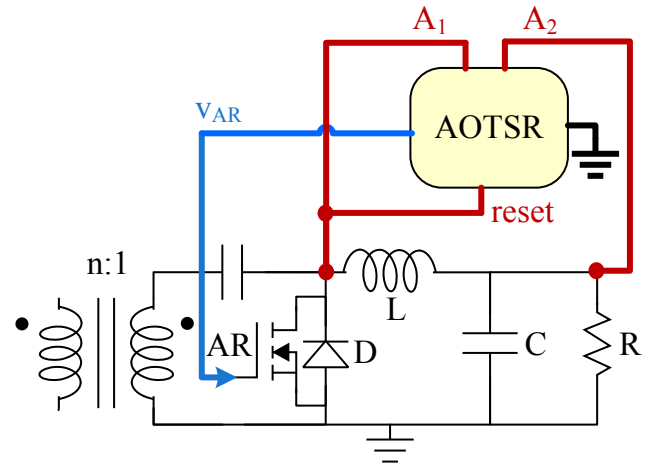

(a)

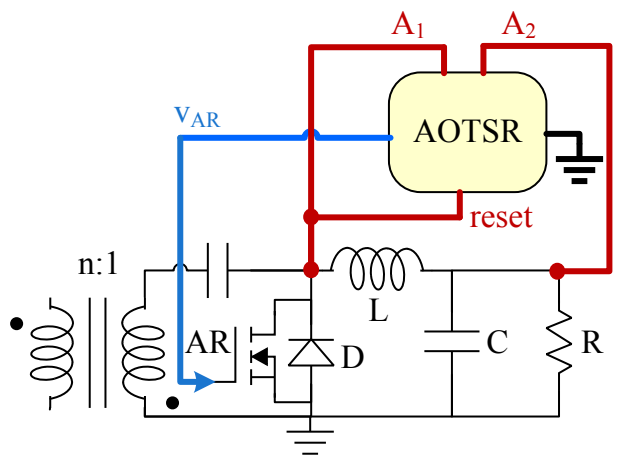

(b)

Figure 11. (a) AOTSR connections for an isolated Zeta converter; (b) AOTSR connections for an isolated Ćuk converter.

\section{A. 100 W Push-Pull converter}

The main specifications of the Push-Pull converter are: $V_{\text {in }}=18-36 \mathrm{~V}, V_{\text {out }}=3.3-5 \mathrm{~V}, L=3.3 \mu \mathrm{H}$ and $C=120 \mu \mathrm{F}$. The transformer has three primary turns and one secondary turn in each winding, and the switching frequency is $115 \mathrm{kHz}$. IRL1404 MOSFETs are used as the main synchronous rectifiers $S R 1$ and $S R 2$; the same model is used for the auxiliar rectifiers $A R 1$ and $A R 2$. General purpose (but matched) transistors (BC557) are used as $T_{1}, T_{2}, T_{3}$ and $T_{4}$ in the AOTSR system. A fast response comparator (AD790) is also used: this is a high performance, expensive comparator, and much cheaper integrated circuits (as the TL3016 used in the following section) could be used. The auxiliar rectifiers are driven by an additional MOSFET driver, UCC27424, supplied from an unregulated voltage obtained from the transformer; according to the specifications of the converter, the supply voltage changed from $6 \mathrm{~V}\left(V_{i n}=18 \mathrm{~V}\right)$ to $12 \mathrm{~V}\left(V_{i n}=36 \mathrm{~V}\right)$. A higher drive voltage can be easily obtained from one of the secondary windings, whose peak voltage is equal to $2 V_{c t}$, therefore providing a voltage ranging from $12 \mathrm{~V}$ to $24 \mathrm{~V}$; a linear regulator is then required to avoid an excessive gate voltage. Table I summarizes the design of the AOTSR. To account for component tolerances, $R_{\text {ramp }}$ has been replaced with a variable resistance to implement a conservative design $(k<0.8)$.

Fig. 12 shows the efficiency measured at different operating conditions, with and without the proposed system: it is apparent that the AOTSR noticeably increases the efficiency
Table I. Design parameters of the AOTSR for the Push-Pull converter.

\begin{tabular}{cccccc}
\hline $\begin{array}{c}\frac{T_{s w}}{2} \\
(\mu \mathrm{s})\end{array}$ & $\mathrm{k}$ & $\begin{array}{c}R_{1} \\
(\mathrm{k} \Omega)\end{array}$ & $\begin{array}{c}R_{2} \\
(\mathrm{k} \Omega)\end{array}$ & $\begin{array}{c}R_{\text {ramp }} \\
(\mathrm{k} \Omega)\end{array}$ & $\begin{array}{c}C_{\text {ramp }} \\
(\mathrm{nF})\end{array}$ \\
\hline 4.35 & 0.8 & 5 & 5 & 3.9 & 1 \\
\hline
\end{tabular}

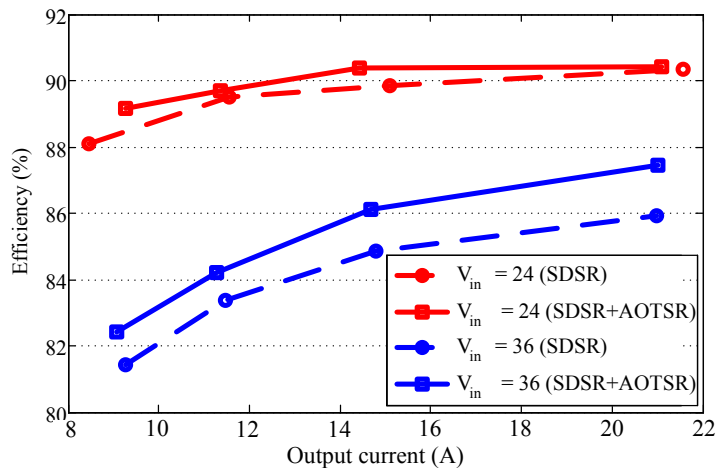

(a)

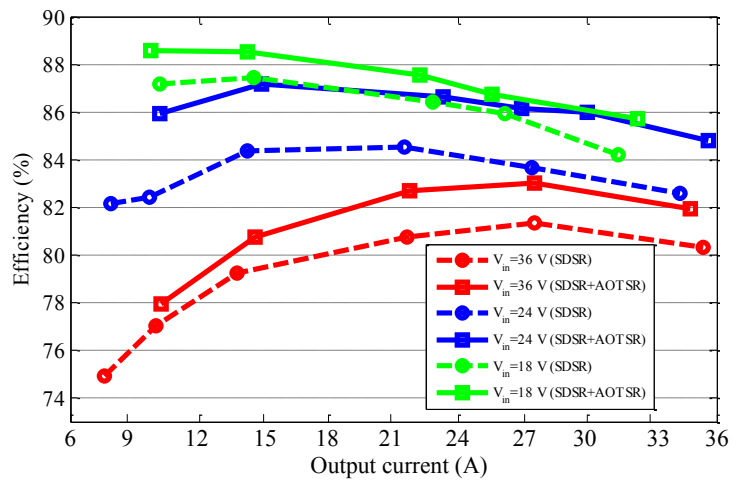

(b)

Figure 12. Measured efficiency with and without the proposed system: (a) $V_{\text {out }}=5 \mathrm{~V}$; (b) $V_{\text {out }}=3.3 \mathrm{~V}$.

regardless of the input and output voltages. The efficiency increase achieved is higher for $V_{i n}=36 \mathrm{~V}$, i.e. when the conduction time of the auxiliar rectifier is longer. Fig. 13 shows several operating waveforms. It can be seen that the proposed system presents the expected adaptive behavior, changing $t_{\mathrm{VAR}}$ according to (14).

Figure 14 shows a sample operating waveform in detail, and Table II shows the values of the parameters highlighted in Fig. 14 for different operating conditions: $t_{d 1}$ and $t_{d 2}$ have to be long enough to guarantee that no overlapping takes place, disregarding of the operating conditions. $t_{d 1}$ is determined by the rising time of $V_{+}$and by the delays introduced by the turnoff of $M_{\text {reset }}$, the comparator and the gate drive circuitry of the auxiliar rectifiers. The rising time of $V_{+}$is in turn determined by $R_{1}$ and the equivalent capacitance at the positive input of the comparator. As overlapping is less likely to take place at the turn-on of the auxiliar rectifiers, the aforementioned delays and the rising time of $V_{+}$should be minimized to maximize the efficiency improvement. Interval $t_{d 2}$ is determined by the value of $k$. The value of $t_{\mathrm{VAR}}$ is also shown in Table II, along with its relative lenght with respect to the dead times and the efficiency improvement achieved $(\Delta \eta)$. 


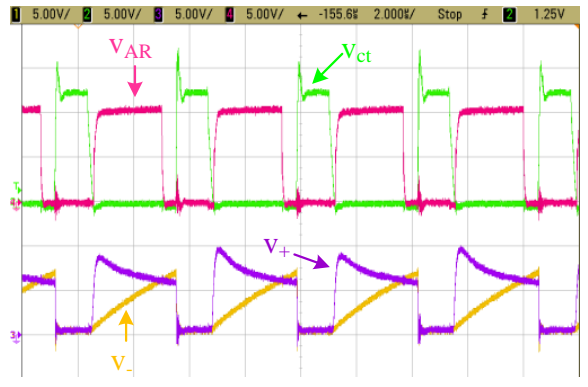

(a)

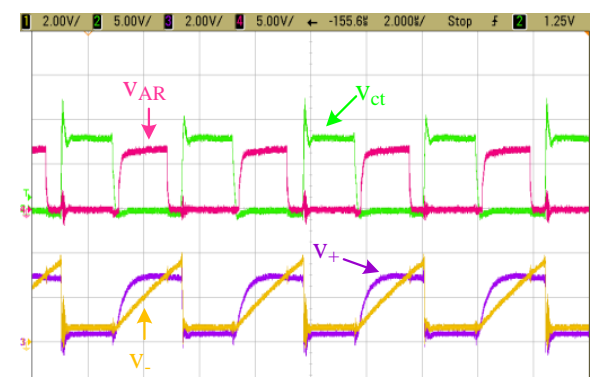

(b)

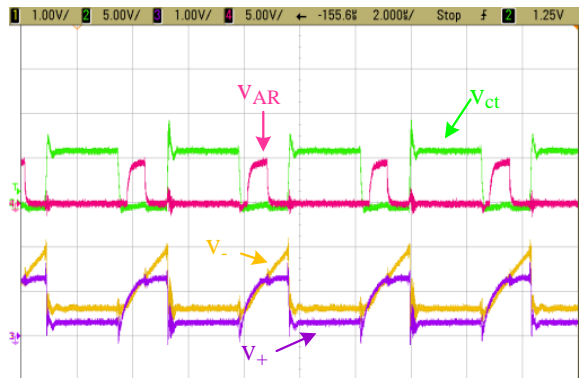

(c)

Figure 13. Experimental waveforms at $V_{\text {out }}=3.3 \mathrm{~V}$ : (a) $V_{\text {in }}=36 \mathrm{~V}$; (b) $V_{\text {in }}=24 \mathrm{~V}$; (c) $V_{\text {in }}=18 \mathrm{~V}$.

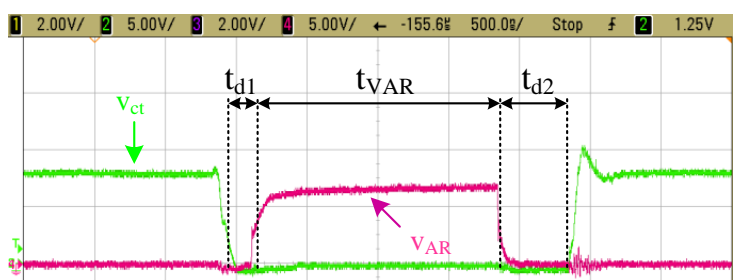

Figure 14. Detail of $v_{A R}$ and $v_{c t}$ in the Push-Pull converter and definition of several important paramenters.

Table II shows several interesting facts. Ideally, and according to (14), $t_{\mathrm{VAR}}$ should remain constant if the input and output voltages are fixed. However, due to nonidealities that have not been taken into account in the analysis (for instance, the voltage peak that appears in $v_{c t}$ ), the actual values of $t_{\mathrm{VAR}}$ might vary. The results shown in Table II demonstrate that $t_{\mathrm{VAR}}$ remains approximately constant for a given input voltage as expected, disregarding of the output power. Furthermore, both $t_{d 1}$ and $t_{d 2}$ change with the operating conditions, too. $t_{d 1}$ changes mainly because the rise time of $V_{+}$depends on the input voltage. The higher $t_{d 1}$, the lower the value of $k$ with respect to the design value: if the variations of $k$ were unacceptable in a certain design, a more accurate adjustment of the peak detector and the minimization of $t_{d 1}$ would be required. $t_{d 2}$ is one of the most important parameters, as it determines the appearance of overlap: it is apparent that it remains approximately constant in the whole operating range, which is the desired behavior. Finally, note that $k$ remains slightly below its maximum design value.

Table II. Parameters highlighted in Fig. 14 for the Push-Pull converter $\left(V_{\text {out }}=3.3 \mathrm{~V}\right)$.

\begin{tabular}{ccccccc}
\hline$V_{\text {in }}$ & $I_{\text {out }}$ & $t_{\mathrm{d} 1}$ & $t_{\mathrm{VAR}}$ & $t_{\mathrm{d} 2}$ & $k=\frac{t_{\mathrm{VAR}}}{(1-2 d) \frac{T_{s w}}{2}}$ & \\
& & & & & & \\
$(\mathrm{~V})$ & $(\mathrm{A})$ & $(\mu \mathrm{s})$ & $(\mu \mathrm{s})$ & $(\mu \mathrm{s})$ & $\%$ & $\%$ \\
\hline \multirow{2}{*}{24} & 7.5 & 0.55 & 1.68 & 0.56 & 62.3 & 2.2 \\
& 15 & 0.55 & 1.7 & 0.52 & 65.3 & 2.8 \\
& 24 & 0.5 & 1.8 & 0.5 & 70.1 & 2.1 \\
\hline \multirow{2}{*}{36} & 7.5 & 0.35 & 2.4 & 0.54 & 76 & 0.7 \\
& 15 & 0.35 & 2.2 & 0.7 & 70 & 1.1 \\
& 24 & 0.3 & 2.1 & 0.7 & 68.5 & 2.1 \\
\hline
\end{tabular}

\section{B. 50 W Flyback converter}

The main specifications of the Flyback converter are: $V_{i n}=$ $36-72 \mathrm{~V}, V_{\text {out }}=5 \mathrm{~V}$ and $C=470 \mu \mathrm{F}$. The transformer has 12 primary turns and 2 secondary turns; the switching frequency is $100 \mathrm{kHz}$. Two 12CWQ03 Schottky diodes are placed in paralell at the secondary side and an IRL1404 was used as the auxiliar rectifier, that is driven by an UCC27424. The supply voltage of the driver is obtained from $V_{s e c}$ using a peak detector and a simple, $5 \mathrm{~V}$ linear regulator. The same circuit described in section IV-A was used, except for the comparator. In this case a low cost, fast response TL3016 from Texas instruments is used. As the maximum supply voltage of the TL3016 is $5 \mathrm{~V}$, slight modifications of the circuit in Fig. 6 are required: different values for the two resistors tied to $T_{1}$ and $T_{2}$ are selected to ensure that the voltage $V_{+}$is never above $5 \mathrm{~V}$, and the values of $C_{\text {ramp }}$ and $R_{\text {ramp }}$ are chosen to compensate this difference. Finally, to minimize the influence of the forward voltage drop of $D_{\text {reset- }}$, which can be noticeable when working with low voltage values, $D_{\text {reset }}$ is replaced by a Schottky diode and $D_{\text {reset+ }}$ is short-circuited. Table III summarizes the design of the AOTSR. Once again, a conservative design with $k<0.8$ has been selected. In this case, the comparator cannot withstand more than $5 \mathrm{~V}$ at any of its inputs; thereby, the component values of the system have been selected to keep $v_{+}$and $v_{-}$below such limit, as long as to fulfill (18). A small filter resistor was added to the peak detector to minimize the effect of the voltage spike that takes place in the Flyback converter.

Fig. 15 shows the efficiency of the converter measured with and without the proposed system. The Flyback converter achieved nearly $83 \%$ efficiency using dissipative clamp and turn-off snubbers. With the AOTSR system the efficiency increased nearly $2.5 \%$, regardless of the input voltage. Note that the efficiency increase achieved is approximately constant in the whole input voltage range, unlike in the results presented in section IV-A; in this case the average current through the

Table III. Design parameters of the AOTSR for the Flyback converter.

\begin{tabular}{cccccc}
\hline $\begin{array}{c}T_{s w} \\
(\mu \mathrm{s})\end{array}$ & $\mathrm{k}$ & $\begin{array}{c}R_{1} \\
(\mathrm{k} \Omega)\end{array}$ & $\begin{array}{c}R_{2} \\
(\mathrm{k} \Omega)\end{array}$ & $\begin{array}{c}R_{\text {ramp }} \\
(\mathrm{k} \Omega)\end{array}$ & $\begin{array}{c}C_{\text {ramp }} \\
(\mathrm{nF})\end{array}$ \\
\hline 11.4 & 0.8 & 15 & 3.3 & 10 & 4.2 \\
\hline
\end{tabular}




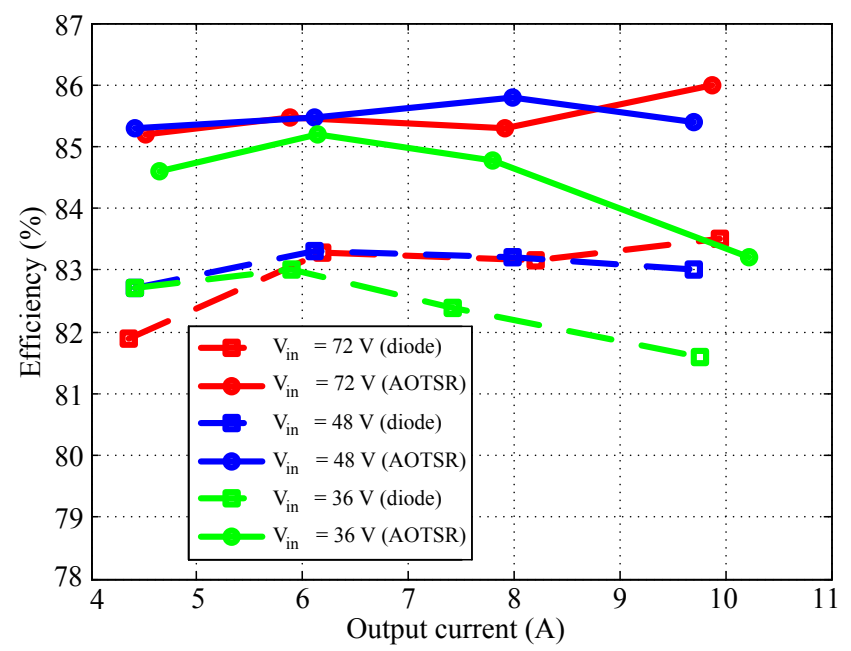

Figure 15. Measured efficiency with and without the proposed system at different operating conditions; the output voltage was $V_{\text {out }}=5 \mathrm{~V}$.

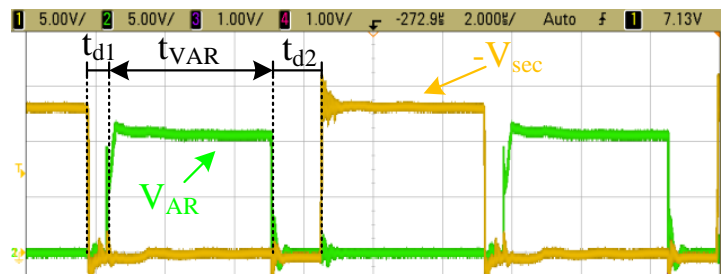

Figure 16. Detail of $v_{A R}$ and $v_{s e c}$ in the Flyback converter and definition of several important parameters.

output diode only depends on the output power and does not change with the input voltage, causing the efficiency increase to remain approximately constant disregarding of the conduction time of the auxiliar rectifier.

Figure 16 shows a sample operating waveform in detail; the same parameters shown in Table II have been measured in the Flyback converter and are shown in Table IV, and the same considerations stated in Section IV-A over $t_{d 1}$ and $t_{d 2}$ can be applied here.

Similar conclusions to those obtained in the previous section can be stated according to the results shown in Table IV. Once again, variations of the actual values of $t_{\mathrm{VAR}}$ are small enough to be neglected for constant input and output voltages. $t_{d 1}$ varies due to the same reasons explained in the case of the Push-Pull converter. $t_{d 2}$ remains approximately constant in the whole operating range, ensuring that no overlap takes place. Finally, $k$ remains slightly below its maximum design value, and changes according to the variations in $t_{d 1}$.

\section{CONCLUSions}

A novel adaptive off-time synchronous rectification system has been presented in this paper. The system is especially suitable for isolated, low output voltage converters, as it uses only information from the secondary side of the transformer; this facts allows complex and sometimes unreliable pulse transmission systems required to transfer the control pulses to the secondary side when synchronous rectification is implemented. The proposed adaptive synchronous rectification system is applicable to converters with symmetrically-driven
Table IV. Parameters highlighted in Fig. 14 for the Flyback converter $\left(V_{\text {out }}=5 \mathrm{~V}\right)$.

\begin{tabular}{cllllccc}
\hline$V_{\text {in }}$ & $I_{\text {out }}$ & $t_{\mathrm{d} 1}$ & $t_{\mathrm{VAR}}$ & $t_{\mathrm{d} 2}$ & $k=\frac{t_{\mathrm{VAR}}}{(1-d) T_{s w}}$ & $\begin{array}{c}\Delta \eta \\
\%\end{array}$ & $\%$ \\
\hline \multirow{2}{*}{36} & 4 & 1 & 3.45 & 1.6 & 57.5 & 1.9 \\
& 6 & 1 & 3.45 & 1.6 & 58.2 & 2.2 \\
& 8 & 1 & 3.45 & 1.6 & 58.2 & 2.38 \\
& 10 & 0.9 & 3.5 & 1.65 & 59 & 2.2 \\
\hline \multirow{2}{*}{48} & 4 & 0.64 & 4.9 & 1.5 & 71.6 & 2.3 \\
& 6 & 0.6 & 4.85 & 1.45 & 71 & 2.27 \\
& 8 & 0.56 & 4.85 & 1.4 & 71 & 2.5 \\
& 10 & 0.52 & 4.9 & 1.4 & 71.6 & 2.7 \\
\hline 72 & 4 & 0.35 & 6.3 & 1.5 & - & 3.1 \\
& 6 & 0.3 & 6.25 & 1.55 & 78.3 & 2.19 \\
& 8 & 0.4 & 6.1 & 1.45 & 76.4 & 2.14 \\
& 10 & 0.45 & 6 & 1.5 & 76 & 2.5 \\
\hline
\end{tabular}

transformers (Half and Full-bridges and Push-Pull) and to converters from the isolated buck-boost family (Flyback, isolated SEPIC, Ćuk and ZETA). The proposed system is simple, inexpensive and can easily be implemented in an integrated circuit. It has been demonstrated that the system is capable of increasing up to a $3 \%$ the efficiency of a $100 \mathrm{~W}$ Push-Pull converter with SDSR, and nearly $2.5 \%$ the efficiency of a 50 W Flyback converter with Schottky diodes. Furthermore, it can reliably work in a wide range of operating conditions due to its adaptive behavior.

\section{REFERENCES}

[1] C. Blake, D. Kinzer, P. Wood "Synchronous rectifiers versus Schottky diodes: A comparison of the losses of a synchronous rectifier versus the losses of a Schottky diode rectifier". IEEE Applied Power Electronics Conference, vol. 1, pp. 17-23, 1994.

[2] J. A. Cobos, J. Uceda, "Low ouput voltage DC/DC conversion". Industrial Electronics, Control and Instrumentation Conference (IECON), vol. 3, pp. 1676-1681, September 1994.

[3] H. Chiu and L. Lin. "A High-Efficiency Soft-Switched AC/DC Converter With Current-Doubler Synchronous Rectification".IEEE Transactions on Industrial Electronics, vol. 52, no. 3, pp. 709-718, June 2005.

[4] J. Blanc, "Practical application of MOSFET synchronous rectifiers". International Telecommunications Energy Conference (INTELEC), pp. 495-501, November 1991.

[5] J.A. Cobos, O. García, J. Sebastián, J. Uceda, "Active clamp PWM forward converter with self driven synchronous rectification". Telecoтmunications Energy Conference (INTELEC), vol. 2, pp. 200-206, September 1993.

[6] M. Jovanović, M. T. Zhang, F. C. Lee, "Evaluation of SynchronousRectification Efficiency Improvement Limits in Forward Converters". IEEE Transactions on Industrial Electronics, vol. 42, no. 4, pp. 387-395, August 1995

[7] X. Xie, J. C. Liu, F. Poon and M. H. Pong. "A novel high frequency current-driven synchronous rectifier applicable to most switching topologies". IEEE Transactions on Power Electronics, vol. 16, no. 5, pp. 635648, September 2001.

[8] A. Fernández, J. Sebastián, P. J. Villegas, M. M. Hernando and L. Álvarez. "Low-power Flyback converter with synchronous rectification for a system with AC power distribution". IEEE Transactions on Industrial Electronics, vol. 49, no. 3, pp. 598-606, June 2002.

[9] J. Zhou, M. Xu, J. Sun and F. C. Lee. "A self-driven soft-switching voltage regulator for future microprocessors". IEEE Transactions on Power Electronics, vol. 20, no. 4, pp. 806-814, July 2005.

[10] M. Xu, Y. Ren, J. Zhou and F. C. Lee. "1-MHz self-driven ZVS Fullbridge converter for $48-\mathrm{V}$ Power Pod and DC/DC brick". IEEE Transactions on Power Electronics, vol. 20, no. 5, pp. 997-1006, September 2005. 


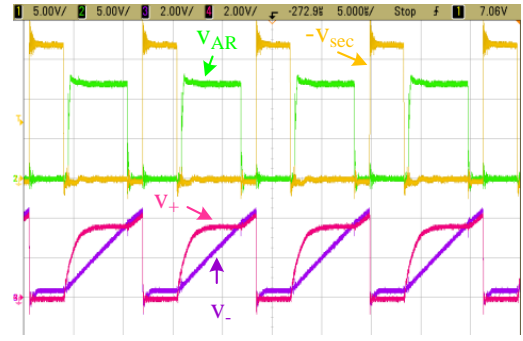

(a)

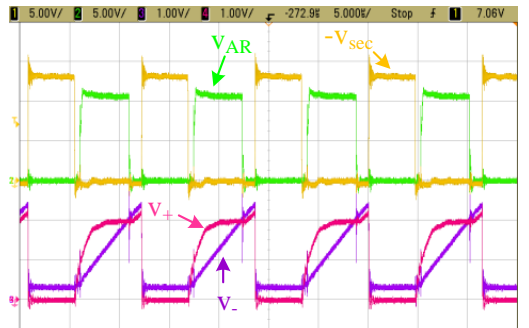

(b)

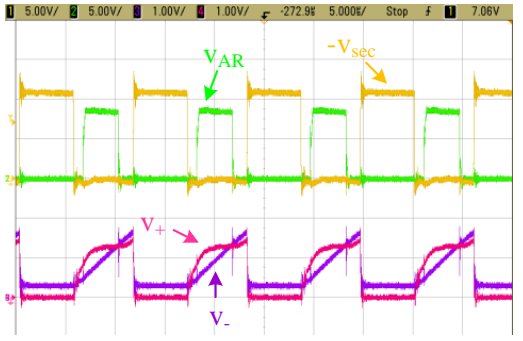

(c)

Figure 17. Experimental waveforms at $V_{\text {out }}=5 \mathrm{~V}$. $V_{t}$ refers to the : (a) $V_{\text {in }}=72 \mathrm{~V}$; (b) $V_{\text {in }}=48 \mathrm{~V}$; (c) $V_{\text {in }}=36 \mathrm{~V}$.

[11] Y. Ren, M. Xu, J. Sun and F. C. Lee. "A family of high power density unregulated bus converters". IEEE Transactions on Power Electronics, vol. 20, no. 5, pp. 1045-1054, September 2005.

[12] D. Fu, F. C. Lee and M. Xu. "A novel driving scheme for synchronous rectifiers in LLC resonant converters". IEEE Transactions on Power Electronics, vol. 24, no. 5, pp. 1321-1329, May 2009.

[13] K. Jin, Y. Sun, M. Xu, D. Sterk and F. C. Lee. "Integrated magnetic self-driven ZVS nonisolated Full-Bridge converter". IEEE Transactions on Industrial Electronics, vol. 57, no. 5, pp. 1615-1623, May 2010.

[14] http://www.power-one.com/resources/products/datasheet/ asq24_family_v7.pdf.

[15] P. Alou, J. A. Cobos, O. García, R. Prieto, J. Uceda, "A new driving scheme for synchronous rectifiers: single winding self-driven synchronous rectification". IEEE Transactions on Power Electronics, vol. 16, issue 6, pp. 803-811, November 2001

[16] A. Fernández, J. Sebastián, M. M. Hernando, P. J. Villegas, J. García, "New self-driven synchronous rectification system for converters with a symmetrically driven transformer". IEEE Transactions on Industry Applications, vol. 41, issue 5, pp. 1307-1315, September-October 2005.

[17] A. Fernández, D. G. Lamar, M. Rodríguez, M. M. Hernando, J. Sebastián and M. Arias. "Self-Driven synchronous rectification system with input voltage tracking for converters with a symmetrically driven transformer". IEEE Transactions on Industrial Electronics, vol. 56, no. 5, pp. 14401445, May 2009.

[18] J. Lee, J. Kwon, E. Kim, W. Choi, B. Kwon. "Single-stage single-switch PFC Flyback converter using a Synchronous rectifier". IEEE Transactions on Industrial Electronics, vol. 55, no. 3, pp. 1352-1365, March 2008.

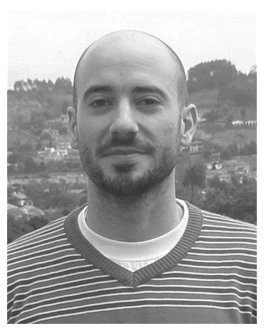

Miguel Rodríguez (S'06) was born in Gijón, Spain, in 1982. He received the M.S. degree in Telecommunication Engineering from the University of Oviedo, Spain, in 2006. Currently he is working towards the Ph.D. degree in the Department of Electrical and Electronic Engineering, also at the University of Oviedo, (granted by the Spanish Ministry of Science and Innovation under the FPU program).

His research interests include DC / DC conversion and power supply systems for RF amplifiers.

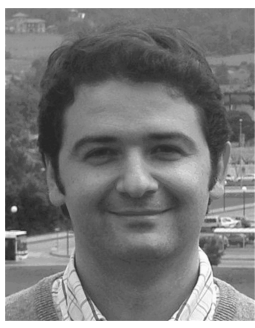

Diego G. Lamar Diego G. Lamar (M05) was born in Zaragoza, Spain, in 1974. He received the M.Sc. degree, and the Ph.D. degree in Electrical Engineering from the Universidad de Oviedo, Spain, in 2003 and 2008 , respectively.

In 2003 he became a Research Engineer at the University of Oviedo and since September 2005, he has been an Assistant Professor. His research interests are switching-mode power supplies, converter modelling and power-factor-correction converters.

$\mathrm{He}$ cooperates regularly with the IEEE and the

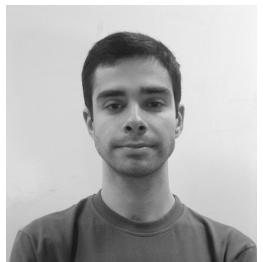

Manuel Arias Manuel Arias Prez de Azpeitia (s05 M'10) was born in Oviedo, Spain, in 1980. He received the M. Sc. degree in electrical engineering from the University of Oviedo, Gijn, Spain in 2005 and the $\mathrm{Ph}$. D. degree in the same university in 2010.

Since February 2005, he has been a Researcher in the Deparment of Electrical and Electronic Engineering, University of Oviedo, developing electronic systems for UPSs and electronic switching power supplies. Since February 2007, he has also been an Assistant Professor of electronics in the same University. His research interests include dc-dc converters, dc-ac converters, UPSs and LED lighting.

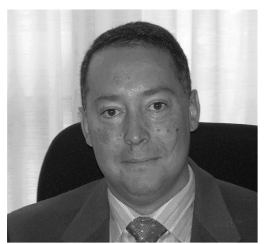

Roberto Prieto Roberto Prieto (M99) received the M.Sc. and Ph.D. degree in electronic engineering from the Technical University of Madrid, Spain, in 1993 and 1998 respectively. Since 1994, he has been an Assistant Professor at the Technical University of Madrid, where he is currently Associate Professor. He has published more than 150 papers in International conferences and journals, most of them from the IEEE. He is also a co-author of two international patents and a technical advisor for several IEEE conferences and journals. He has been the advisor on more than 20 masters theses and 5 doctoral theses and has participated in more than 50 research projects as a research engineer. His main research interest is the design and modeling of magnetic components.

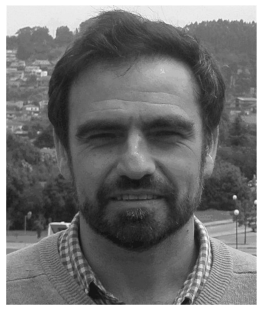

Javier Sebastián Javier Sebastin (M87) was born in Madrid, Spain, in 1958. He received the M.Sc. degree from the Polytechnic University of Madrid, and the Ph.D. degree from the University of Oviedo, Spain, in 1981 and 1985, respectively. He was an Assistant Professor and an Associate Professor at both the Polytechnic University of Madrid and at the University of Oviedo, in Spain. Since 1992, he has been with the University of Oviedo, where he is currently a Professor. His research interests are switching-mode power supplies, modelling of dc-todc converters, low output voltage dc-to-dc converters and high power factor rectifiers. 